\title{
Practical guide of references and nutritional recommendations for individuals affected by Coronavirus Disease 2019
}

\author{
Hadassa Hillary Novaes Pereira Rodrigues ${ }^{1}$, Wanderson Hugo Drescher ${ }^{2}$, Katiuchia Pereira Takeuchi ${ }^{3}$, Fernanda \\ Cacilda dos Santos Silva ${ }^{4}$, Ana Carolina Pinheiro Volp ${ }^{5 *}$
}

${ }^{1}$ Federal University of Mato Grosso, Faculty of Medicine, Cuiabá, MT, Brazil. ${ }^{2}$ Federal University of Mato Grosso, Faculty of Nutrition, Cuiabá, MT, Brazil. ${ }^{3}$ Federal University of Mato Grosso, Faculty of Nutrition, Department of Nutrition and Food, Cuiabá, MT, Brazil. ${ }^{4}$ Federal University of Ouro Preto, Institute of Exact and Biological Sciences, Department of Biological Sciences, Ouro Preto, MG, Brazil. ${ }^{5}$ Federal University of Mato Grosso, Faculty of Nutrition, Department of Nutrition and Food, Cuiabá, MT, Brazil.

\begin{abstract}
Fast and exponentially spreading, COVID-19 pandemic has affected the entire world and caused a collapse in health systems to, due to the short contagion time, the need for hospitalization and intensive care. Of the affected, some portion needs hospitalization and essential nutritional support. Considering the current demand on the need to better inform and prepare health professionals and the general population in a simplified mode, given a huge amount of disseminated information, the objective of this work was to present a summarized and practical guide of references and nutritional recommendations for individuals affected by COVID-19. Bibliographic review about this subject related publications was carried out on scientific websites, including the main themes: critical patient, nutritional status, nutritional recommendations, immunity and coronavirus. The following items were included and presented very clearly in this guide: screening for nutritional risk; administration routes, objectives and guidelines of nutritional therapy; dietary and nutritional recommendations; immunomodulation; probiotics; and liquids/hydration. This article has summarized what is available on the subject in the literature up to now. We believe that this practical guide will facilitate and optimizes the conduct of health professionals.
\end{abstract}

Keywords: Critical patient, Nutritional status, Nutritional recommendations, Inflammation, COVID19.

Citation: Hadassa Hillary Novaes Pereira Rodrigues et.al. (2020) Practical guide of references and nutritional recommendations for individuals affected by Coronavirus Disease 2019, Journal of PeerScientist 3(2): e1000023.

Received: June 21, 2020; Accepted: July 29, 2020; Published: August 08, 2020.

Copyright: (C) 2020 Hadassa Hillary Novaes Pereira Rodrigues et.al. This is an open-access article distributed under the terms of the Creative Commons Attribution License, which permits unrestricted use, distribution, and reproduction in any medium, provided the original author and source are credited.

Funding: This research received no specific grant from any funding agency in the public, commercial, or not-for-profit sectors, apart from the authors personal resources.

Competing Interests: The author have declared that no competing interests exist.

* E-mail: anavolp@gmail.com | Phone: (+55 65) 3615-8812

\section{INTRODUCTION}

$\mp \mathrm{n}$ n extremely recent history, December 2019, an outbreak of pneumonia of unknown cause was recorded in Wuhan, China. Then, it was discovered that the zoonotic disease is caused by the severe acute respiratory syndrome virus (SARS-CoV-2), which has become widely known as coronavirus disease 2019 (COVID-19). Fast and exponentially spreading, a worldwide pandemic, which has been causing a collapse in health systems due to the short time of contagion, the need for hospitalization and intensive care [1]. Currently there are 8.641.120 million confirmed cases worldwide, where the largest epicenters of the disease are the United States with 2.221.079 million, Brazil with 1.032.913 million and Russia with 568.292 thousand cases [2]. Brazil has 48.954 million deaths, where the largest cities São Paulo and Rio de Janeiro are most affected [3]. Data were obtained from Johns Hopkins University monitoring on June 20, 2020. The Ministry of Health continues to recommend isolation and social distancing measures and is supported by Brazilian state and municipal decrees [4]. There is still no robust scientific evidence regarding effective medications and/or cure for this disease [4,5], however it has been recommended to use a balanced diet in quality and quantity, colored and that amplifies the immune system [6]. Recently, potential antiviral compounds from marine bivalves, worth evaluating against SARS-CoV-2 have been proposed [7].

The main symptoms are fever, shortness of breath and tiredness, which may be mild, moderate or asymptomatic. The incubation period is 4 days, ranging from 2-7 days. $80-85 \%$ of those infected have a mild form of the disease, however the rest who require hospitalization, is mostly elderly and/or people with 
comorbidities (heart disease, chronic kidney disease, respiratory diseases and diabetes) [4].

According to the Brazilian Intensive Care Association (Associação de Medicina Intensiva Brasileira - AMIB 2020), approximately $20 \%$ corresponds to severe cases in which patients experience a critical illness with the mechanical ventilation demand [4]. In critically ill patients, the literature has shown that the majority have reduced levels of serum hemoglobin and na extensive infiltration of neutrophils in pulmonar capillaries [8]. A peculiar hematological situation is suggested, in which there is a decrease in hemoglobin and an increase in heme iron, therefore, cells react with elevated serum ferritin to bind to iron ions in an attempt to reduce damage, thus the high accumulation of iron ions further contributes to the inflammatory cascade [4,6]. It is also reiterated for Brazilian Association of Intensive Care Medicine, that ventilatory weaning may be delayed due to the slowdown in stabilizing the hemodynamic and ventilatory parameters, which are directly related to the patient's nutritional status $[9,10]$.

Nutritional support, is necessary and prophylactic for complications of nutritional status such as malnutrition, sarcopenia, muscle weakness, beyond increasing survival, reducing the incidence of deaths, readmissions and early reintubations $[9,11]$. It is already very well evidenced in the scientific literature that patients in intensive care, present nutritional risk as an independent factor, and the worsening of the nutritional status is predicted when they are elderly, immunosuppressed or have comorbidities. Moreover, anabolic resistance and dysglycemia are present in the flow phase of critical illness, which increases the negative clinical outcomes [9,11-13].

The Government of India, Ministry of AYUSH (Ayuverda, Yoga \& Naturopathy, Unani, Siddha and Homoeophathy), published the guidelines for AYUVERDA practitioners for COVID-19 [14]. This Guideliness focuses in four target groups and includes a flow chart of protocol of management of COVID based in preventive, therapeutic and promotive action. The four targets groups are: 1) Quarantine and home isolation subjects with or without corona positive test and health workers; 2) Subjects with mild, severe symptoms, comorbid and immune-comprommised condition; 3) Vulnerable group (pregnant and lactating women, children and geriatric subjects); and 4) Post-treatment restorative healthcare [14]. During the COVID pandemic (lockdown period), it is very dificult to follow any of the physical activities, and this inertia may lead to indigestion and related health issues. The ayurveda prescribes food regime as a part of the treatment, and the crucial concept of ayurveda regarding the type of diet is in the form of sattvic, rajasic and tāmasik food that helps a person maintain the physical equilibrium to sustain and manage good health in critical conditions like COVID-19 [15]. Still, there is a strong relationship between the gut and the mind, since proper sleep is vital to digest the food and enhances immunity [15-16].

Another condition directly related to the patient's nutritional status is sarcopenia, a muscle condition characterized by progressive and/or generalized skeletal muscle loss, whose muscle function is the primary parameter for its probable diagnosis [10]. It is important to point out that from the fifth decade of life, there is a slow and progressive decrease in muscle mass, which is intensified in the seventh decade of life, according to Aging Guideline of BRASPEN [17]. Another concern is the secondary sarcopenia in intensive care patients with prolonged hospitalization [13]. Patients submitted to long-term orotracheal mechanical ventilation, are more prone to ICU acquired sarcopenia or to present muscle weakness during hospitalization or after hospital discharge. Muscle weakness is common in those who have undergone intensive care, characterized by symmetrical and bilateral flaccid paresis, being more pronounced in the proximal than distal muscles, with generally reduced reflexes. Such complication is associated with increased mortality, prolonged hospital stay and mechanical ventilation $[10,13]$.

In view of the aforementioned, it is essential that assistance and emergency actions of nutritional care be substantiated and referenced for facilitating the access to nutritional therapy professionals who are in the front line fighting against Coronavirus disease 2019. Thus, given the clinical and public health relevance of the subject in question, the objective of this article was to summarize and compile the main evidence about nutritional recommendations for COVID-19 patients hospitalized in intensive care or wards.

This study consisted of a bibliographic review concerning the national and international studies that relate the main theme. The literature review was carried out based on the available journals on the portal of the Coordenação de Aperfeiçoamento de Pessoal de Nível Superior (CAPES) and on the main health databases: MedLine, Lilacs, PubMed and SciELO. The used systematization included the analysis and interpretation of material that contained the citation of "coronavirus" plus the following words (critical patient, nutritional status, nutritional recommendations, inflammation). Results will be presented clearly and succinctly, in the following sequence: screening for nutritional risk; administration routes, objectives and guidelines of nutritional therapy; dietary and nutritional recommendations; immunomodulation; probiotics; and liquids/hydration. 


\section{Recommendations for nutritional state assessment}

\section{Nutritional risk screening}

- Ideally, Nutritional Risk Screening must be performed within the first 24 hours after admission $[18,19]$.

- Resources used to perform screening: telenutrition, telephone, secondary data from the multidisciplinary team records $[11,18]$.

- In addition to the aforementioned resources, criteria designed to determine nutritional risk based on the main risk factors can be used (consider at least 1 factor): elderly (> 65 years), adult with BMI $<20.0$ $\mathrm{kg} / \mathrm{m}^{2}$, patients at high risk or pressure injury, immunosuppressed, inappetent, persistent diarrhea, history of weight loss, chronic obstructive pulmonary disease (COPD), asthma, structural lung diseases, heart diseases (including major arterial hypertension), insulin-dependent diabetes, renal failure, pregnant [18].

- Patients who stay in the ICU for more than 48 hours must be considered at risk of malnutrition $[11,20]$.

\section{Administration routes, objectives and guidelines of nutritional therapy}

Non-critically ill patients:

Oral feeding

- Preferable oral feeding (OF) $[11,19,21]$.

- Oral feeding supplementation (OFS) is indicated when the estimated caloric intake is less than $60 \%$ of the nutritional needs [11].

- It must be started, preferably, by OF associated with nutritional education work and OFS when necessary [22].

- OFS must be used whenever possible to attend the patient's needs, when dietary advice is not sufficient to achieve the goals. At least $400 \mathrm{kcal} /$ day with $30 \mathrm{~g}$ of protein or more must be provided at least during one month [22].

\section{Enteral and parenteral feeding}

- In polymorbid and elderly patients whose nutritional needs cannot be attended by $\mathrm{OF}$, initiate enteral nutrition (EN) administration. Consider parenteral nutrition $(\mathrm{PN})$ when $\mathrm{EN}$ is not indicated or unable to achieve goals [20].

- Prone position: Avoid fasting! Initiate EN after the first hour in the prone position (PP), until one hour before returning to the supine position. Do not suspend PN to perform the maneuver. Continuous EN is recommended, in an infusion pump with a hypercaloric and high protein formula, without fibers in trophic or low volume (up to $20 \mathrm{ml} / \mathrm{h}$ ), during the PP period or the first 06 days without damage to the patient [11].

- It is suggested that the EN be maintained in case of compensated or permissive hypercapnia. Suspend the diet in case of decompensated hypoxemia, hypercapnia or severe acidosis [11].

- EN must be delayed in the presence of uncontrolled shock, unmet hemodynamic and tissue perfusion goals, hypoxemia, hypercapnia or uncontrolled acidosis with life-threatening [20].

- Monitor the difference between prescribed and received EN as a marker of dietary acceptance [23].

- Modules: avoid (Less manipulation, less chance of team contamination. So, avoided infection) [11].

- In cases of patients with dysphagia after extubation, OF with texture adaptation can be adopted, if it is not safe EN must be administered. Post-pyloric positioning in cases with a very high risk of bronchoaspiration. If none of the options are possible, temporary NP is indicated during swallowing training [20].

- Nutritional therapy (NT) is a holistic treatment. Therefore, the TN's plan, method, route and formula must be adjusted in a dynamic and appropriate manner. Carefully observe how to assess and deal with adverse events in a timely manner [22].

\section{Dietary and Nutritional Recommendations for Adults and Seniors}

\section{Calories for Acute Phase}

- Initiate with 15 to $20 \mathrm{kcal} / \mathrm{kg} /$ day and progress to 25 $\mathrm{kcal} / \mathrm{kg} /$ day after the 4 th day of patients' recovery [11].

- Initiate a low-calorie or trophic diet, progressing slowly to a full dose during the first week of the critical illness, with a caloric target of 15-20 $\mathrm{kcal} / \mathrm{kg} /$ day [19].

- Do not exceed $25 \mathrm{kcal} / \mathrm{kg} /$ day $[11,24]$ OR 27 $30 \mathrm{kcal} / \mathrm{kg} / \mathrm{day}[18,19]$. High risk of overfeeding;

- According to disease severity, supply 20-30 $\mathrm{kcal} / \mathrm{kg} /$ day [22].

- $25-30 \mathrm{kcal} / \mathrm{kg} / \mathrm{day}$ for general patients [21].

- $27 \mathrm{kcal} / \mathrm{kg} /$ day for polymorbid patients above 65 years [20].

- $30 \mathrm{kcal} / \mathrm{kg} / \mathrm{day}$ for severe polymorbid patients with low weight, whose objective must be reached with caution, because there is a refeeding syndrome risk [20].

- Note: In case of low levels of phosphorus, potassium and magnesium, postpone the caloric evolution until the correction of their serum levels [11]. 


\section{Proteins for acute phase}

- 1.5-2.0 g/kg/day of protein (also in case of renal dysfunction) [11].

- Suggestion of progression: $0.8 \mathrm{~g} / \mathrm{kg} /$ day on the $1 \mathrm{st}$ and $2 \mathrm{nd}$ days; $0.8-1.2 \mathrm{~g} / \mathrm{kg} /$ day at $3-5 \mathrm{th}$; and $>1.2$ $\mathrm{g} / \mathrm{kg} /$ day after the 5 th day [11].

- 1.3 to $1.5 \mathrm{~g} / \mathrm{kg} /$ day for general patients [24].

- High protein, polymeric - $1.5-2.0 \mathrm{~g} / \mathrm{kg} / \mathrm{day}$ [19].

- $1 \mathrm{~g} / \mathrm{kg} /$ day for elderly, individually adjusted according to disease status and tolerance [20].

- $\geq 1 \mathrm{~g} / \mathrm{kg} /$ day in polymorbid patients, in order to avoid weight loss, complications risk, hospital readmission and provide better functional result [20].

- With increased protein requirements, provide 1.0-2.0 $\mathrm{g} / \mathrm{kg} /$ day to increase the supply of branched chain amino acids (BCAA) [22].

- BCAA supplementation can significantly inhibit muscle degradation, improve insulin resistance and increase the effectiveness of Interferon-gamma [22].

- Supplementation of 3g/day of beta-hydroxy-betamethylbutyrate (HMB) can significantly increase protein anabolism and inhibit protein catabolism [22].

- Reach from 1.2 to $2.0 \mathrm{~g} / \mathrm{kg} /$ day [21].

- For patients with intestinal lesions, it is recommended formulas with small peptides (oligomeric or monomeric) to facilitate their absorption and use [21].

- For patients with preserved intestinal functions, it is recommended formulas with whole proteins (polymeric) [21].

- Proportion of non-protein calories/grams of nitrogen is from 100 to $150 / 1$ [22].

- Providing protein sources in a balanced way daily, in at least 3 meals, is more conducive to protein synthesis [22].

\section{Carbohydrates and Lipids}

- Do not use formulas with a high lipid/low carbohydrate content to manipulate respiratory coefficient and reduce $\mathrm{CO}_{2}$ production in critically ill patients with pulmonary dysfunction [11].

- For patients with hyperglycemia, formulas for glycemic control are recommended [21].

- Give preference to medium and long chain fatty acids (FA) to increase the proportion of omega-3 and omega-9 [22].

- 30:70 percent lipid/carbohydrate energy ratio for patients on spontaneous breathing or non-invasive ventilatory support [20].

- 50:50 percent lipid/carbohydrate energy ratio for patients on mechanical ventilation [20].

- Omega-9 FAs have an immuno-neutral effect, since they have less interference with hemodynamics and endothelial cell function [22].

\section{Micronutrients}

For elderly with deficient serum levels, supplementation is recommended

- Vitamin D: 400 - 4000 UI/day [24].

- Vitamin E: 134 - 800 mg/day [24].

- Zinc: 20 - $220 \mathrm{mg} /$ day [24].

- Vitamin C: 200 mg - 2 g/day [24].

\section{For all life stages}

- Vitamin D supplementation is indicated for hospitalized patients with deficient serum levels [24].

- Seek to meet the daily doses of fat-soluble Vitamins (A, E and D) and water-soluble ones (such as complex B and C), minerals (such as Zinc, Selenium and Iron) and omega-3 fatty acid for nutritional risk or malnourished patients [20].

- Vitamin C supplementation is effective for Acute Respiratory Distress Syndrome (ARDS) caused by viral infections [22].

- Daily supplement a variety of vitamins and minerals, especially B1, vitamin C, selenium and zinc [22].

- Attention to serum phosphorus: hypophosphatemia signals refeeding syndrome and may increase the duration of ventilatory support in critically ill patients and induce failure after ventilatory weaning $[11,23]$.

\section{Immunomodulation}

- Enteral formula with omega-3, borage oil and antioxidants is not indicated for patients with Acute Respiratory Disease Syndrome (ARDS) [11].

- In general, the indication of omega-3 apparently makes no difference to the patient [11].

- Some studies indicate that low levels of omega-3 associated or not with other micronutrients and immunonutrients corroborate for negative clinical outcomes [20].

- Arginine supplementation can significantly increase the thymus weight, improve T-cell function and promote wound healing [21-22].

\section{Probiotics}

There are reports of intestinal dysbiosis in patients with COVID-19, resulting in a significant reduction of lactobacillus and bifidobacterium, which can lead to intestinal bacterial translocation, intestinal-derived infection and gastrointestinal symptoms (abdominal pain and diarrhea). Therefore, it is important to maintain the balance of the intestinal microbiome through probiotics and the adequate nutritional support [21].

\section{Liquids / Hydration}


- For patients with large areas of pulmonary consolidation or advanced age, it is recommended to control the intravenous fluids amount [22].

- In stable patients, is indicated $30-40 \mathrm{ml} / \mathrm{kg} /$ day of fluids. For every $1{ }^{\circ} \mathrm{C}$ increase in body temperature, supplement with 3-5 ml/kg [22].

\section{CONCLUSION}

This review presents clinical relevance, since it constitutes a simplified but meaningful practical guide about the nutritional recommendations for Coronavirus disease. Items like were screening for nutritional risk; administration routes, objectives and guidelines of nutritional therapy; dietary and nutritional recommendations; immunomodulation; probiotics; and liquids/hydration were included and presented very clearly in this guide. We believe that these themes will possibly facilitate and optimize the conduct of health professionals and potentially improves the patients outcome, increasing their chances of survival.

\section{REFERENCES}

1. Wu, Zunyou, and Jennifer M. McGoogan. "Characteristics of and important lessons from the coronavirus disease 2019 (COVID-19) outbreak in China: summary of a report of 72314 cases from the Chinese Center for Disease Control and Prevention." Jama 323.13 (2020): 1239-1242.

2. COVID, Coronavirus. "Global Cases by the Center for Systems Science and Engineering (CSSE) at Johns Hopkins University (JHU). JHU COVID-19 Resource Center. Johns Hopkins Coronavirus Resource Center. 2020." (19).

3. Brasil. Coronavírus Brasil. Ministério da Saúde. 2020 [accessed on 19 June 2020]. p. 1. Available from: https://covid.saude.gov.br/

4. Coronavírus - AMIB [Internet]. Associação de Medicina Intensiva Brasileira. 2020 [accessed on 19 June 2020]. Available from: https://www.amib.org.br/pagina-inicial/coronavirus/

5. Basha, Syed Hussain. "Corona virus drugs-a brief overview of past, present and future." Journal of PeerScientist 2.2 (2020): e1000013.

6. Rodrigues HHNP, et.al. "Prático de referências e recomendações nutricionais para indivíduos acometidos pelo coronavírus e para a população em isolamento social durante a pandemia: COVID-19". Braspen J. 2.35 (2020):1816.

7. Yap, Chee Kong. "Antiviral compounds from marine bivalves for evaluation against SARS-CoV-2." Journal of PeerScientist 2.2 (2020): e1000015.

8. Barnes, Betsy J., et al. "Targeting potential drivers of COVID-19: Neutrophil extracellular traps." Journal of Experimental Medicine 217.6 (2020).

9. Liu, Wenzhong, and Hualan Li. "COVID-19: attacks the 1-beta chain of hemoglobin and captures the porphyrin to inhibit human heme metabolism." Preprint revised on 10.04 (2020).

10. Parra BFCS, et al. "Proposta de protocolo para sarcopenia em pacientes internados". Braspen J. 34.1 (2019):58-63.

11. Campos, Letícia Fuganti, et al. "Parecer BRASPEN/AMIB para enfrentamento do COVID 19 em pacientes Hospitalizados." Braspen J 35.1 (2020): 3-5.

12. Cruz-Jentoft AJ, et al. "Sarcopenia: revised European consensus on definition and diagnosis. Age Ageing" 2019 Jan 1 [accessed on 20 June 2020]; 48.1 (2019):16-31.Available from: https://academic.oup.com/ageing/article/43/2/157/11593
13. Van Aanholt DPJ, et al. "Diretrizes Brasileira de Terapia Nutricional". Braspen J. 2018;1(2525-7374):37-55.

14. Ayushi $M$ of. Guidelines for Ayurveda practitioners for COVID 19. MINISTRY OF AYUSH, Editor. Government of India International Institute for Democracy and Electoral Assistance (International IDEA) [accessed on 28 April, 2020] p. 46. Available from: http://aiia.gov.in/wp-content/uploads/2020/06/ayurveda.pdf

15. Ayushi Sunil Lohi, Gaurav Sawarkar. "Management Of Diet During Covid-19 Pandemic". Int J Res Pharm Sci 11 (2020):1547.

16. Sharma, Luxita. "Dietary management to build adaptive immunity against COVID-19." Journal of PeerScientist 2.2 (2020): e1000016.

17. Gonçalves T, et al. "Diretriz BRASPEN de Terapia Nutricional no Envelhecimento. Supl Diretrizes" Braspen Ter Nutr. 34.Supl 3 (2019):58-2019.

18. Piovacari, Silvia Maria Fraga, et al. "Fluxo de assistência nutricional para pacientes admitidos com COVID-19 e SCOVID19 em unidade hospitalar." Braspen J [Internet] 35.1 (2020): 6-8.

19. Martindale, R., et al. "Nutrition therapy in the patient with COVID-19 disease requiring ICU care." Nutrition Society of Critical Care Medicine and the American Society for Parenteral and Enteral Nutrition (2020): 1-8.

20. Barazzoni, Rocco, et al. "ESPEN expert statements and practical guidance for nutritional management of individuals with SARSCoV-2 infection." (2020): 1631-1638.

21. Yu, KY, and HP Shi. "Explanation of expert recommendations on medical nutrition for patients with novel coronavirus pneumonia." Zhonghua yi xue za zhi 100.10 (2020): 724-728.

22. Liang, Tingbo. "Handbook of COVID-19 prevention and treatment." The First Affiliated Hospital, Zhejiang University School of Medicine. Compiled According to Clinical Experience (2020): 68.

23. Barbas, Carmen Sílvia Valente, et al. "Brazilian recommendations of mechanical ventilation 2013. Part 2." Revista Brasileira de terapia intensiva 26.3 (2014): 215.

24. Por Juandy Gómez "Sociedad de Nutrición Enteral y Parenteral brinda recomendaciones ante el COVID-19" [accessed on 19 June 2020]. Available from:https://www.diariodesalud.com.do/textodiario/mostrar/1857417/sociedad-nutricion-enteral-parenteralbrinda-recomendaciones-ante-covid-19

Submit your next manuscript to Journal of PeerScientist and take full advantage of:

- High visibility of your research across globe via PeerScientist network

- Easy to submit online article submission system

- Thorough peer review by experts in the field

- Highly flexible publication fee policy

- Immediate publication upon acceptance

- Open access publication for unrestricted distribution

Submit your manuscript online at:

http://journal.peerscientist.com/

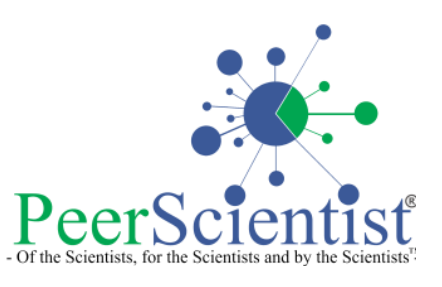

